\title{
Fis Europhysics Notes
}

\section{ILL Refurbishment and Membership}

The UK's SERC Council decided last July that it wished to make an unambiguous commitment to the Rutherford Appleton Lab's ISIS pulsed neutron spallation source and to renegotiate the terms of SERC membership in the Institut Laue-Langevin neutron research facility in Grenoble. Sir Mark Richmond, the SERC Chairman, speaking last month at a study meeting for a nextgeneration European Spallation Source (ESS), one of a series of workshops sponsored by the EC following a report of a 1990 study panel [EN 22 (1990) 62], interpreted this as maintaining ISIS funding until 1997. Some efficiency savings should be possible in view of improving performance (from $1989 / 90$ to 1991 , the average ISIS proton beam current increased by $\approx 40 \%$ and the total integrated beam delivered by $\approx 26 \%$ ). Savings to accommodate 1991 cuts in the UK science budget would thus have to come mainly through renegotiating the ILL agreement.

Sir Mark pointed out that the SERC could have simply recommended termination of the agreement as from the end of 1993 and argued that the sequence of events was such that the Council's decisions were not influenced by the breakdown of the ILL's reactor last year.

The ILL Associates meeting in February recommended a reactor refurbishment based on replacing the reactor vessel, which could be carried out within the normal operating budget over two years. As the SERC share would be about $\mathrm{f} 10 \mathrm{M}$, Sir Mark said it is "...important that the UK is a member of ILL post 1993 for a reasonable period..." (a 10 year agreement has been proposed) and that "...full financial commitment to the refurbishment of the reactor has to be related to the negotiations for our continuing membership". While discussions on the renegotiation continue, the Associates have released funds to start dismantling the reactor and have asked for further information on technical aspects of the refurbishment. ILL staff might also be expected to collaborate in a $18-24$ month design study which will be proposed to the EC in May to define the work required to implement the accelerator, target station and instrumentation for the ESS.

\section{AUSTRON}

The promoters of an Austrian initiative to create an international research centre tentatively called AUSTRON argue that European unification calls for competitive, regional-based scientific structures. The initiative has evolved from possible centres for crystal growth and detector technology to a neutron spallation source based on a rapid cycling 0.8-1.5 MeV proton synchrotron, initially having twice the peak flux of the comparable 0.8 Mev ISIS source. While dwarfed

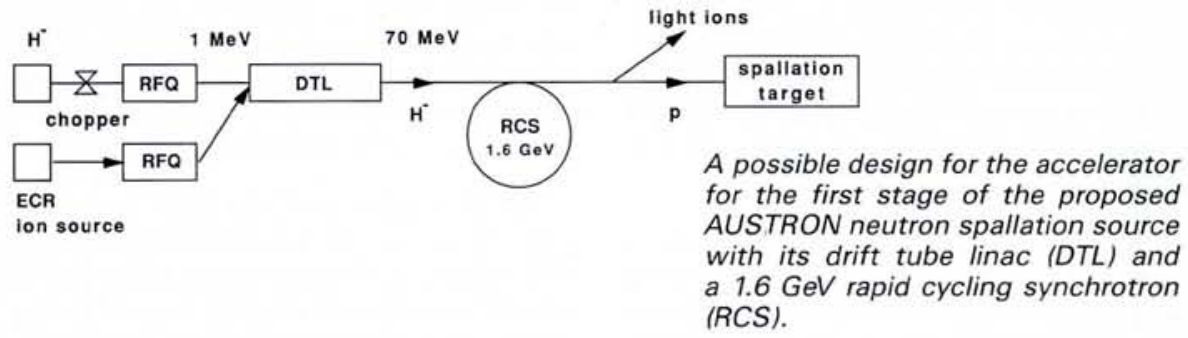

by a possible ESS which is unlikely to operate before 2005, AUSTRON would need only about 5 years to complete, and minor additions could allow use as a light-ion accelerator serving a broad constituency.

CERN hosted a working group meeting of experts from 50 European institutes last October and M. Regler, Secretary General of the AUSTRON Study Group of the Austrian Academy of Sciences, writes to say that Erhard Busek, the Austrian science minister, recently announced that he will move towards internationalising the proposal. This will involve seeking national contributions and exploring links to the six-country Hexagonale collaboration. The next technical step would be a detailed design study.

\section{Budapest's Neutron Facility}

Neutron sources for scattering work are relatively undeveloped in east and central Europe, particularly those based on refurbished reactors. The Geman government has decided to shut down the research reactor at Rossendorf in the former GDR while the reactor at the Nuclear Research Institute at Rez in Czechoslovakia is primarily used for isotope production. It is thus heartening that Dr. Lazlo Rosta, Head of the Neutron Physics Lab at the KFKI in Budapest, announced at a recent neuton scattering conference in the UK that the KFKI is planning to restart its relatively small $10 \mathrm{MW}$ research reactor for scattering studies, nuclear research, radiography, and in-pile irradiation. The KFKI, the Central Research Institute for Physics of the Hungarian Academy of Sciences, became formally divided into five legally independent institutes belonging to the Academy on $1 \mathrm{Ja}$ nuary, with the central body confined to providing services.

The four-year refurbishment after incident-free operation from 1959 was completed at the end of 1990 . The plan is to apply for an operating licence in March, once the local population has been consulted, with regular operation of $3600 \mathrm{~h} / \mathrm{a}$ targetted for January 1993 using 8 thermal beams and 3 guided beams leading to a new instrument hall. The reactor belongs to the central KFKI

body and is staffed by the KFKI Atomic Energy Research Institute pending a possible reorganisation once the operating licence is obtained. A scientific centre has been proposed to cater for a regular users community (which did not exist historically) and support under the EC's PHARE Programme for access to a planned cold source is being sought, together with possible links to the so-called Hexagonale initiative to build up regional intermediate-scale research facilities.

\section{- European Community}

In spite of calls for proposals for the EC's human capital and mobility programme in the 3rd Framework Programme for science and technology being further delayed until at least April, the Commission of the EC issued on 4 March documents to set in motion discussions leading to decisions on the next Framework programme (for 1994-8). The meeting in Maastricht of the heads of state last year means that unanimous approval by all Members States (as at present) and the European Parliament are required. However, Parliament need now only be consulted once instead of twice on specific programmes.

\section{US Budget Proposals}

The US Administration's proposed 1993 budget for science and technology only seeks an increase from the 1992 budget approved by Congress by an amount equivalent to slightly less than the forecast inflation rate of $3.3 \%$. But a continuing cut (by $7 \%$ to $53 \%$ ) in military spending in favour of civilian R. \& D. brought a sigh of relief. The National Science Foundation gains the most with an $18 \%$ increase to mainly boost four priority programmes (in biotechnology, materials, computer science, and climate change) involving $40 \%$ of its budget. The Department of Energy also came out ahead with a $11 \%$ increase, including a $34 \%$ increase (to $650 \mathrm{M} \$ \mathrm{US}$ ) for the SSC collider. NASA fared less well with a $3.3 \%$ increase. Congress is unlikely to vote approval before September.

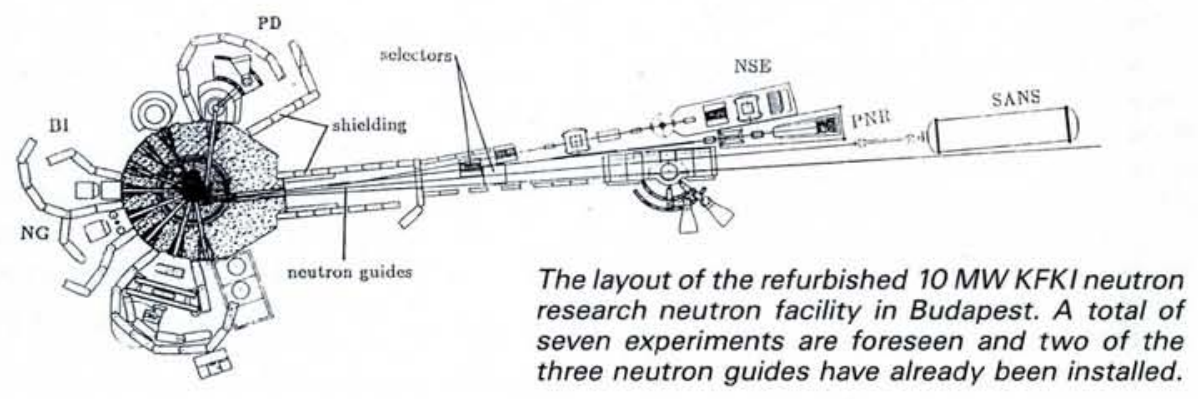

